\title{
Role of probiotics in respiratory tract diseases with special reference to COVID-19: A review
}

\author{
Aditi Munmun Sengupta', Diptendu Chatterjee'2, Rima Ghosh ${ }^{3}$ \\ ${ }^{1}$ Research Scholar, Department of Anthropology, University of Calcutta; Medical Officer, CK Birla Hospitals, Dept. of \\ Critical Care, Kolkata; Harvard Medical School Post Graduate Association Member, ${ }^{2}$ Assistant Professor (Stage III), \\ Department of Anthropology, University of Calcutta; Deputy Registrar, University of Calcutta, ${ }^{3}$ Junior Research Fellow \\ (UGC-NET), Department of Anthropology, University of Calcutta
}

According to the International Scientific Association in association with Food and Agriculture Organization of United Nations(UN) and World Health Organization(WHO), "administration of probiotics" means administration and ingestion of live microorganisms in an appropriate amount for developing good health condition in the host individual. Probiotics are administered for building immunity against common respiratory tract infections, including cough, pharyngitis, laryngitis, pneumonia, and asthma. Therefore, vaccinations have been introduced to safeguard the children and the elderly from such infections. General patients improve their health when they consume appropriate amounts live microorganisms (probiotics) such as Lactobacillus and Bifidobacterium that belong to lactic acid bacteria family. Fermented foods, such as yogurt and soy, and dietary supplements are known to be rich sources of microorganisms. However, the consumption of microorganisms causes gastrointestinal symptoms as common side effects. Limited studies provide relevant information about the probiotics' consumption; therefore, the current study aimed to increase the probiotics consumption among individuals and avoid common infections.

Key words: Probiotics; Respiratory tract infections; Dietary supplements; Ventilator-associated pneumonia; COVID-19

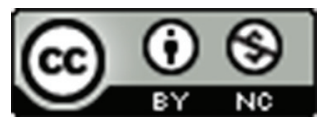

This work is licensed under a Creative Commons Attribution-NonCommercial 4.0 International License.

\section{INTRODUCTION}

As per the previous studies, similarities have been identified between the respiratory system and pathophysiology of the gastrointestinal system. This is because many research studies confirmed that the microbiome is a significant component that is necessary for intestinal inflammation, where the creation of a healthy microbiome contributes to a reduction of many ailments. The consumption of probiotics in the form of dietary supplements is beneficial for health as it helps avert seasonal illnesses, prevent infection state, remove ailment signs, and reduce the duration of disease. Furthermore, relevant research studies are to be conducted to acquire information about probiotic-host immune system crosstalk through which actions could be developed to prevent or treat respiratory tract infections and ailments. ${ }^{1}$

Probiotics are responsible for improving the intestinal barrier functionaries by developing local pathogens and are known to play a safeguarding role. Considering the pleiotropic effect, probiotics are also responsible for the systemic functioning of a mucosal immune system linked with the host body. Additionally, probiotics are performing the role functionary related to $\mathrm{T}$ regulatory cells that are major contributors of proinflammatory cytokines that augment the generation of $\mathrm{T}$ helper cells. However, the extent of a generation of $\mathrm{T}$ helper cells is highly dependent on the strength, strain, and stimulus of probiotic bacteria administered in the form of therapy. Moreover, the biological activity that is conducted by probiotics is affected by growing and arrangement techniques that are 
responsible for immunomodulatory and inflammatory effects. ${ }^{2}$

The respiratory tract infections can be classified into two parts, namely, upper respiratory tract and lower respiratory tract infections. The upper respiratory tract ailments and infections include common cold, pharyngitis, otitis media, and sinusitis. Conversely, the lower respiratory tract ailment and infections include bronchitis and pneumonia. Probiotics help modulate the immune response of the individuals by choosing maximum strains in the specific body parts such as lungs. However, studies related to it are limited in the literature academia and do not provide sufficient information about the probiotic mechanism on lung infections. It is necessary to research this segment as probiotics are extensively used to treat and prevent allergic reactions, respiratory tract infections, and other lung diseases. ${ }^{3}$

Clinical reports associated with benefits offered by probiotics against respiratory tract infections and ailments are under review lately. ${ }^{4,5}$ The research and investigations are conducted by considering the children and geriatric patients who are mostly affected by upper respiratory tract diseases such as common cold. To protect the patients, the probiotics developed with the combination of Lactobacillus and Bifidobacterium species are used to prevent respiratory tract ailments. The patients who are given combinations of probiotics have shown fewer incidences of infections such as placebo. Hence, it is suggested that antibiotics could be used with probiotics to treat patients. ${ }^{4}$

According to the systematic review, ${ }^{6}$ related to the randomized clinical trials, probiotics could be used to treat children with upper respiratory tract and lower respiratory tract infections. The clinical trial was performed by taking into consideration 2417 children aging 10 years or younger showing symptoms of acute otitis media, respiratory ailments, and common cold or flu. The children were given probiotics treatment based on their signs, symptoms, and diagnoses and were observed for 6-7 months. It was found that the symptoms of the disease have been reduced and the onset of new episodes of infections in comparison with the placebo communities has been deterred. Hence, the use of antibiotics for the treating of respiratory-based infections has reduced, and there is an increase in the use of probiotics among patients in comparison with placebo communities. Additionally, the opinions, viewpoints, and observations of physicians and doctors directly associated with child care and caregiving are considered. It reflected the better performance of probiotics among individuals than of antibiotics Table 1. The only limitation to the study was that all the observation and information were related to developed countries that have a strong mechanism of community well-being and healthcare provisions. The study did not include facts related to developing countries that are having limited healthcare conditions. Consequently, the study did not include facts related to the performance of probiotics when the individuals do not have accessibility to sanitation and hygiene and were infected by respiratory tract infections.

This study recommends the standardization of probiotic use, which is based on the investigation conducted in developing countries that are having less per capita income. ${ }^{6}$

Another double-blind randomized controlled study assessed the effect of a fermented dairy product containing the probiotic element L. casei DN-114001 at a dose of $200 \mathrm{~g} / \mathrm{d}$ for 4 months on the incidence and severity of gastrointestinal and respiratory infections in free living elderly people during winter season. The duration of all pathologies was found to be significantly lower in the treatment group of free living elderly people of median age 76 years (sample size $=537$ ) than in the control group provided with non-fermented dairy product (sample size $=535$ ). The study showed a prospect of reduction in the episode ( 6.5 vs. 8 days in control group, $\mathrm{p}=0.008$ ) and cumulative duration ( 7 vs. 8 days in control group, $\mathrm{p}=0.009$ ) of upper respiratory infections (URTI) with administration of probiotics in the elderly.Conclusion was drawn that consumption of a fermented dairy product containing the probiotic strain L. casei DN-114 001 in elderly was associated with a decreased duration of URTI, Lower respiratory tract infections (LRTI) andGastrointestinal tract infections (GITI) in comparison with the control group, particularly for URTI such as rhinopharyngitis. The fermented product containing the probiotic strain was found to be safe and well tolerated in the selected population (Table-1). ${ }^{?}$

The administration of probiotics was also tested on animals, which suggested that probiotics are also beneficial for animals. For example, in a study, ${ }^{7}$ probiotics, such as Lactobacillus and Bifidobacterium, were used to treat ovalbumin (OVA)-sensitized mice.

Methacholine response rate in mice was recorded after OVA inhalation, and it was found that mice were suffering from pulmonary inflammation. The examination of the condition of mice was conducted by using bronchoalveolar lavage fluid (BALF) along with mediators and inflammatory cells. The research outcomes showed that mice had a reserved reaction to methacholine. The symptoms included breathlessness and wheezing due to the presence of cholinergic agents and tested the functioning of the respiratory tract was impaired. It was recorded that after the provision of probiotics, the 


\section{Table 1:Studies on probiotics and respiratory diseases}

\begin{tabular}{|c|c|c|c|}
\hline Place and Date & Authors & Study & Result \\
\hline Brazil (2015) & $\begin{array}{l}\text { GV de Araujo, } \\
\text { MH de Oliveira Junior, } \\
\text { DM Peixoto, S Emanuel, } \\
\text { ES Cavalcanti. }{ }^{6}\end{array}$ & $\begin{array}{l}\text { A clinical trial was performed on } 2417 \\
\text { children up to } 10 \text { years of age. They were } \\
\text { administered probiotics for } 6-7 \text { months } \\
\text { and observed by doctors and caregivers. }\end{array}$ & $\begin{array}{l}\text { This trial showed a decrease in the use of } \\
\text { antibiotics with an increase in probiotics } \\
\text { use. }\end{array}$ \\
\hline France (2010) & $\begin{array}{l}\text { E Guillemard, F Tondu, F } \\
\text { Lacoin, J Schrezenmeir. }^{7}\end{array}$ & $\begin{array}{l}\text { A multicentric study involving } 537 \text { male } \\
\text { and female individuals of atleast } 70 \text { years } \\
\text { of age, free living (non-institutionalized) } \\
\text { were asked to consume } 200 \mathrm{~g} / \text { day of a } \\
\text { dairy product containing the probiotic strain } \\
\text { Lactobacillus casei DN-114001, and the } \\
\text { control group of sample size } 535 \text { was given } \\
\text { non-fermented dairy product. The duration } \\
\text { of the study was for } 3 \text { months with an } \\
\text { additional } 1 \text { month follow-up. The baseline } \\
\text { and demographic characteristics of the } \\
\text { volunteers were taken into consideration. }\end{array}$ & $\begin{array}{l}\text { The fermented product was found to } \\
\text { significantly reduce both the average } \\
\text { duration of URTI, LRTI, and GITI per } \\
\text { episode and the cumulative duration of } \\
\text { the infection spectra. These reductions } \\
\text { were statistically significant in the } \\
\text { product consumption phase and also } \\
\text { for the duration of the study as a whole } \\
\text { (product consumption phase plus follow- } \\
\text { up phase) when all the infections were } \\
\text { considered. Significant reductions were } \\
\text { also reported for all URTI and specifically } \\
\text { for rhinopharyngitis. }\end{array}$ \\
\hline $\begin{array}{l}\text { Switzerland } \\
(2010)\end{array}$ & $\begin{array}{l}\text { S Hougee, AJMVriesema, } \\
\text { SCWijering, LMJ } \\
\text { Knippels, G Folkterts, } \\
\text { F P Nijkamp, J Knol, } \\
\text { J Garseen. }^{8}\end{array}$ & $\begin{array}{l}\text { A study where ovalbumin-sensitized } \\
\text { mice were administered with probiotics in } \\
\text { different combinations. }\end{array}$ & $\begin{array}{l}\text { Satisfactory result was seen based } \\
\text { on parameters such as degree of } \\
\text { pulmonary inflammation (reduced) and in } \\
\text { bronchoalveolar lavage fluid (reduction of } \\
\text { mediators like interleukin } 4 \text {, interleukin } 5 \text {, } \\
\text { interleukin 10, OVA-specific IgE and IgG1, } \\
\text { and inflammatory cells like eosinophils). }\end{array}$ \\
\hline
\end{tabular}

volume of eosinophils in BALF has been reduced. It was observed that the cytokine levels of interleukin 4, interleukin 5, and interleukin 10 in BALF along with OVA-specific IgE and IgG1 have also been reduced (Table-1). ${ }^{8}$

\section{Mechanism of action of probiotics in the respiratory tract}

The mechanism of different probiotics tends to be different, and the exact mechanism related to actions or framework of probiotics is still in the investigational status. The study of multiple mechanisms of probiotics is necessary to identify the features of probiotics and the diseases that could be treated with them. The most common supposition associated with probiotics is microbe-host interaction and microbe-microbe interaction. It is vital to ensure the appropriate amount and combination of probiotics to safeguard the health interests of the individuals. The other features that are to be considered while preparing probiotics for individual consumption are their origin in humans, resistance to antibiotics, antimicrobial materials, adhesion to epithelial cells, and food additive tolerance capacity. Survival in the gastrointestinal transit, the safety of host, immune modulator activity, stability in the food matrix, and acid and bile resistance are also included. ${ }^{9,10}$

The commonly available probiotics contain microorganisms, such as Bifidobacterium, Lactobacillus, and Streptococcus, that belong to the lactic acid bacteria family. However, with the advancement in the probiotic studies, new species are also introduced in the carrying out of probiotic treatment. ${ }^{11}$
The extent and reach of probiotics application have reached the gut system along with the respiratory tract. The probiotics-based frameworks are highly dependent on the workings of the pathogen microorganisms. Thus, probiotics are also responsible for creating and enhancing immunomodulation, reinforcing the epithelial obstacle functionaries, and creating matters that show antimicrobial activity directly related to pathogen bacteria. ${ }^{12}$

\section{Immunomodulatory role of probiotics}

The implications related to immunomodulatory effects play a significant role in the adaptability of probiotics and provide reliable information related to the effect of probiotics concerning inflammatory conditions and immune aspects among individuals that are suffering from gastrointestinal tract issues. The use of probiotics is highly beneficial in treating indirect implications related to respiratory tract ailments along with different allergic conditions. ${ }^{13}$

Studies show that strains of Lactobacillus inhibit cytokine trail when there is the availability of IL-1. Conversely, another study revealed that the use of probiotics helps augment neutrophil, leukocyte, and natural killer cell counts. ${ }^{14}$ Moreover, it has been identified that probiotics are highly responsible for lowering the inflammatory cytokine expression that helps treat ailments such as tumor necrosis factor-a, IL-1b, and IL-8. ${ }^{15}$ The use of probiotics also helps in maintaining a higher level of salivary immunoglobulin A that is actively involved in the production of bacteriocins that exhibit antimicrobial symptoms (Figure 1). ${ }^{16}$ 


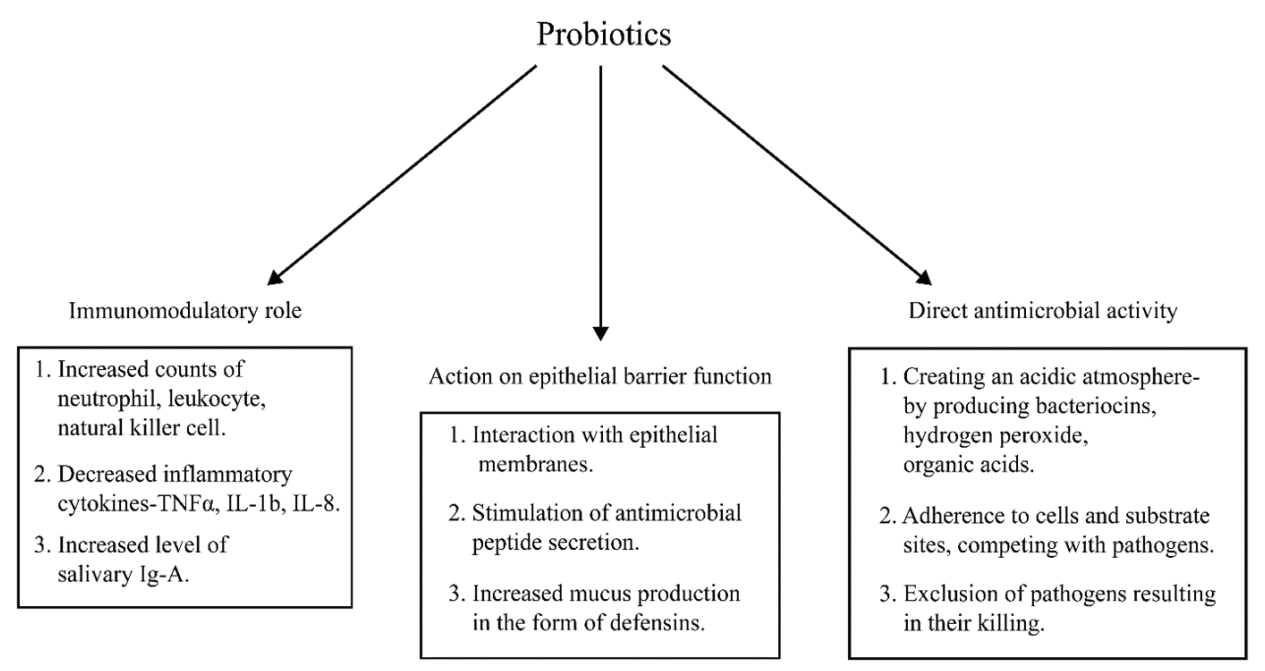

Figure 1: Mechanism of action of probiotics in the respiratory tract

\section{Probiotics activity on epithelial barrier function}

Probiotics help to reduce the harmful effects of pathogens by establishing interactions with epithelial membranes that are present in the host body. ${ }^{17}$ It is also observed that the stimulation of antimicrobial peptide secretion and mucus secretion in the form of defensins is highly helpful in reinforcing the epithelium obstacle functionary in the host (Figure 1).

\section{Direct antimicrobial activity of probiotics}

The implications of using probiotics in the form of bacteriocins, hydrogen peroxide, and organic acids are responsible for creating an acidic atmosphere. These observations could be traced because of the production of antimicrobial agents and direct microbial implications of probiotics in the respiratory tract of individuals. Moreover, there is a competition between probiotics and pathogens for the attainment of cellular adhesion and substrates sites. This also shows restraining the generation of virulence attributes when there is a secretion of antimicrobial compounds. It results in pathogens nullifying that impact the toxicity and metabolic features of the probiotics and pathogens. Moreover, mucin produced with the help of probiotics inhibits high adherence to the pathogenic microorganisms as they are beneficial for supplementing the host's defense mechanism (Figure 1). ${ }^{18}$

\section{Probiotics and respiratory diseases}

The ailments associated with URTI such as sinusitis, rhinosinusitis, pharyngitis, laryngotracheobronchitis, and otitis were considered for purposes of study concerning probiotics that include those that contained the strains of, Lactobacillus casei, Lactobacillus fermentum VRI003, Lactobacillus Plantarum, Bifidobacterium breve 99, Bifidobacterium longum SP 07/3 and those that were used for treating the patients as a single or combined treatment form. It was found that the use of probiotics helped in the treatment of respiratory infections by reducing acute episodes. It also helped in reducing the extent of the episode in chronic diseases (Table-2). ${ }^{19,20}$

The study examined the facts that were associated with cystic fibrosis bronchopneumonia episodes that were commonly found among patients suffering from respiratory infections. The use of probiotics containing Lactobacillus rhamnosus GG helps reduce the high incidence level of infections in patients and individuals. As per another study, the effective use of Lactobacillus rhamnosus GG for about 6 months decreases exasperated pneumonia episodes in the patients that were having issues of cystic fibrosis and Pseudomonas aeruginosa (Table 2). ${ }^{21}$

There are certain studies conducted by scholars that suggested that probiotics are highly helpful in preventing nosocomial pneumonia. Nosocomial pneumonia is mainly related to the ailment in which the respiratory tract colonization is present because of the presence of pathogenic bacteria such as Pseudomonas aeruginosa. The use of probiotics that contain Lactobacillus rhamnosus and Lactobacillus Plantarum helps in treating prophylaxis diseases (Table 2). ${ }^{22}$

However, to gain better insights about probiotics action and framework concerning prophylaxis, more studies are required in the segment of respiratory tract diseases. The best way to administer and make use of probiotics is by performing oropharyngeal or nasogastric administration. However, the acceptance of studies based on these aspects is limited, and not much attention has been paid in this field. ${ }^{23}$

\section{Probiotics and Pneumonia}

The characteristics of pneumonia include an inflammatory condition that highly affects the body organs such as lungs in 
Table 2: Respiratory diseases and Probiotics

\begin{tabular}{lll}
$\begin{array}{l}\text { Types of Respiratory Tract } \\
\text { Infections (RTIs) }\end{array}$ & Probiotics & Results \\
\hline $\begin{array}{l}\text { Upper RTI, such as sinusitis, } \\
\text { rhinosinusitis, pharyngitis, } \\
\text { laryngotracheobronchitis, and otitis }\end{array}$ & $\begin{array}{l}\text { Lactobacillus casei, Lactobacillus } \\
\text { fermentum VRI 003, } \\
\text { Lactobacillusplantarum, } \\
\text { Bifidobacterium breve } 99\end{array}$ & $\begin{array}{l}\text { Satisfactory results with reduction of acute episodes of } \\
\text { diseases and the episodes in chronic diseases }{ }^{19,20}\end{array}$ \\
& $\begin{array}{l}\text { Bifidobacterium longum SP 07/3 } \\
\text { Lactobacillus rhamnosus GG }\end{array}$ & $\begin{array}{l}\text { Verified the reduction of exasperated pneumonia episodes } \\
\text { in cystic fibrosis and issues with Pseudomonas aeruginosa }{ }^{21}\end{array}$ \\
Nosocomial pneumonia & $\begin{array}{l}\text { Lactobacillus plantarum and } \\
\text { Lactobacillus rhamnosus }\end{array}$ & $\begin{array}{l}\text { Prophylactic treatment in reducing the colonization by } \\
\text { pathogenic bacteria like Pseudomonas aeruginosa }{ }^{22}\end{array}$ \\
\hline
\end{tabular}

the air sacs known as alveoli. It is mainly due to the presence of microorganisms such as bacteria and viruses. The mechanism related to the use of probiotics on pneumonia includes two hypotheses. The first hypothesis is that the administration of the probiotic will help in the reduction of a high concentration of pathogens. This includes the patients that are suffering from pneumonia, oropharyngeal, and other pneumonia-related gastric issues. ${ }^{24,25}$ The second hypothesis is related to modulation of immune response concerning probiotics and highly associated with mucosarelated lymphatic tissues that are present in the digestive mucosa and respiratory organ. In respect to this, seven investigational studies were conducted and found that the performance of probiotics helps in improving the condition of patients that are suffering from pneumonia (VAP) and using a ventilator. ${ }^{26-28}$ The provision of probiotics did not result in any adverse side effect; however, a significant reduction was found in the mortality of patients that were treated with probiotics. The treated patients were included in the subgroup that belonged to the sepsis category. The reactions of the double-blind randomized controlled medical testing of patients that are kept in intensive care were recorded. It was found that the patients that were kept on the mechanical ventilation pneumonia observation showed high acceptance of probiotics as there was a reduction in mortality rates. Hence, it can be concluded that probiotics help in combating the microbial activity produced by pathogens and preventing severe infections that cause sepsis.

\section{Probiotics and Coronavirus disease 2019}

The spread of coronavirus disease 2019 (COVID-19) has set alarms globally. It was declared to be a pandemic by the World Health Organization, and many countries such as the United States, the United Kingdom, Italy, and India are facing issues due to the rise in the COVID-19 confirmed cases.

Focusing on the symptoms of COVID-19 patients, few patients showed intestinal microbial dysbiosis that reduced with the use of probiotics such as Bifidobacterium and Lactobacillus. Additionally, the use of probiotics helped in balancing intestinal microbiota that lowered the risk of moving toward secondary infection, which is mainly due to bacterial translocation. ${ }^{29}$

The presence of colonic microflora highly impacts the systemic and mucosal immunity of individuals. It is to be treated with probiotics as it helps in the promotion of microecological balance among the disinfectants. ${ }^{30,31}$ Furthermore, probiotics are also highly useful in stimulating the immune system and enhancing the immune reactivity of the individuals. The investigations conducted by scholars also prescribe efficient use of probiotics for the treatment of allergic components. ${ }^{32.33}$

Considering the most recent studies in the field, the National Health Committee and National Administration of Traditional Chinese Medicine of the People's Republic of China in February 2020, suggested the use of probiotics in patients with severe COVID-19. ${ }^{34}$ A study published in April 2020 stated from non peer-reviewed animal studies that Lactobacillus acidophilus and Bacillus clausii did not reduce the corona virus receptor expression in the murine small intestine compared with control and post-salmonella infection model. ${ }^{35}$

The limitations of probiotics in the application of treatment in the case of inflammatory storms, stern and sensitive medical events, and COVID-19 disease infected individuals are still unknown. Hence, intensive research is required in this direction to provide more details about the applicability of probiotics under such conditions. However, probiotics are found to be performing well only in the case of general immunity and do not help in preventing particular diseases among the large populace. Therefore, it recommended that in the times of crises, the right combination of probiotics will help in ensuring the good health conditions of infants, pregnant women, and the elderly. ${ }^{36}$

By considering the above review of literature and discussion about the probiotics and its application, it can then be said that probiotics could be included in the 
treatment process as it helps rehabilitate disease by using classification methods.

\section{CONCLUSIONS}

The research was limited as the exact role of probiotics concerning COVID-19 could not be determined, and the applicability of probiotics in the case of gut and lung infections is still ongoing. However, few research studies clearly show that probiotics help in improving gut function and build healthy lungs. The use and impact of probiotics highly depend on the strains of probiotics, time of use, mode of administration, and frequency of incidence of new episodes of upper and lower respiratory tract infections among individuals who are having good health conditions. The study included the facts based on probiotics studies conducted in developed countries where the medical health conditions were good, and individuals were provided with sanitation and other basic healthcare facilities. It also included that the individuals followed the guidelines related to probiotics ingestion, and no reports of adverse probiotics ingestion were observed. However, there is an intensive need to conduct probiotics study in the case of developing countries where the cases of respiratory infections among the populace are higher than in developed countries that are having less per capita income.

\section{ACKNOWLEDGMENTS}

We express our heartfelt thanks to the Scholars and Professors of Dept. of Anthropology, University of Calcutta and CK Birla Hospital Doctors and Staffs for their continuous support in this project. Acknowledging the contributions of Enago (www.enago.com) for the English language review.

\section{REFERENCES}

1. Mortaz E, Adcock IM, Folkerts G, Barnes PJ, Paul Vos $A$ and Garssen J. Probiotics in the management of lung diseases. Mediators Inflamm 2013; 751068.

https://doi.org/10.1155/2013/751068

2. Oelschlaeger TA. Mechanisms of probiotic actions-a review. Int J Med Microbiol 2010; 300:57-62.

3. NICE Short Clinical Guidelines Technical Team. Respiratory tract infections - antibiotics prescribing. Prescribing of antibiotics for self-limiting respiratory tract infections in adults and children in primary care. London: National Institute for Health and Clinical Excellence; 2008.

4. Hao Q, Lu Z, Dong BR, Huang CQ and Wu T. Probiotics for preventing acute upper respiratory tract infections. Cochrane Database Syst Rev 2011; 7:CD006895.

5. Popova M, Molimard P, Courau S, Crociani D, Dufour C, Le Vacon $F$, et al. Beneficial effects of probiotics in upper respiratory tract infections and their mechanical actions to antagonize pathogens. J Appl Microbiol 2012; 113:1305-1318.
6. de Araujo GV, de Oliveira Junior MH, Peixoto DM, Emanuel S and Sarinho ES. Probiotics for the treatment of upper and lower respiratory-tract infections in children: systematic review based on randomized clinical trials. J Pediatr (Rio J) 2015; 91:413-427.

7. Guillemard E, Tondu F, Lacoin F and Schrezenmeir J. Consumption of a fermented dairy product containing the probiotic Lactobacillus casei DN-114001 reduces the duration of respiratory infections in the elderly in a randomised controlled trial. Br J Nutr 2010;103(1):58-68.

https://doi.org/10.1017/S0007114509991395

8. Hougee S, Vriesema AJM, Wijering SC,Knippels LM, Folkerts G, Nijkamp FP, et al. Oral treatment with probiotics reduces allergic symptoms in ovalbumin-sensitized mice: a bacterial strain comparative study. Int Arch Allergy Immunol 2010; 151:107-117.

9. Iacono A, Raso GM, Canani RB, Calignano A and Meli R. Probiotics as an emerging therapeutic strategy to treat NAFLD: focus on molecular and biochemical mechanisms. J Nutr Biochem 2011; 22:699-711.

10. Havenaar R, Huis IJHJ. Probiotics: a general view. In: Wood B.J.B. (eds) The Lactic Acid Bacteria in Health and Disease. Vol 1. Boston, MA: Springer, 1992, p.151-170.

11. Baquerizo Nole KL, Yim E and Keri JE. Probiotics and prebiotics in dermatology. J Am Acad Dermatol 2014; 71:814-821.

12. Goldin BR and Gorbach SL. Clinical indications for probiotics: an overview. Clin Infect Dis 2008; 46 Suppl 2: S96-S100.

13. Björkstén B. Effects of intestinal microflora and the environment on the development of asthma and allergy. Springer Semin Immunopathol 2004; 25: 257-270.

14. Guillemard E, Tanguy J, Flavigny A, de la Motte $S$ and Schrezenmeir J. Effects of consumption of a fermented dairy product containing the probiotic Lactobacillus casei DN114001 on common respiratory and gastrointestinal infections in shift workers in a randomized controlled trial. J Am Coll Nutr 2010; 29:455-468.

15. Oliva S, Di Nardo G, Ferrari F, Mallardo S, Rossi P, Patrizi G, et al. Randomised clinical trial: the effectiveness of Lactobacillus reuteri ATCC 55730 rectal enema in children with active distal ulcerative colitis. Aliment Pharmacol Ther 2012; 35:327-334.

16. Fooks LJ and Gibson GR. Probiotics as modulators of the gut flora. Br J Nutr 2002; 88 Suppl 1:S39-S49.

17. Walker WA. Mechanisms of action of probiotics. Clin Infect Dis 2008; 46:S87-S91.

18. Fuller R. (ed), Probiotics, The Scientific Basis. London. Chapman and Hall, 1992.

19. Hao Q, Lu Z, Dong BR, Huang $C Q$ and Wu T. Probiotics for preventing acute upper respiratory tract infections. Cochrane Database Syst Rev 2011; CD006895.

20. Popova M, Molimard P, Courau S, Crociani J, Dufour C, Le VaconF, et al. Beneficial effects of probiotics in upper respiratory tract infections and their mechanical actions to antagonize pathogens. J Appl Microbiol 2012; 113: 1305-1318.

21. Wolvers D, Antoine JM, Myllyluoma E, Schrezenmeir J, Szajewska $\mathrm{H}$ and Rijkers GT. Guidance for substantiating the evidence for beneficial effects of probiotics: prevention and management of infections by probiotics. J Nutr 2010; 140:698S-712S.

22. Morrow LE and Kollef MH Recognition and prevention of nosocomial pneumonia in the intensive care unit and infection control in mechanical ventilation. Crit Care Med 2010; 38:S352-S362.

23. Charlson ES, Bittinger K, Haas AR, Fitzgerald AS, Frank I, Yadav A, et al. Topographical continuity of bacterial populations in the healthy human respiratory tract. Am J Respir Crit Care Med 2011; 184: 957-963. 
24. Morrow LE, Kollef $\mathrm{MH}$ and Casale TB. Probiotic prophylaxis of ventilator-associated pneumonia: a blinded, randomized, controlled trial. Am J Respir Crit Care Med 2010;182:1058-1064.

25. Forestier C, Guelon D, Cluytens V, Gillart T, Sirot J and De Champs C. Oral probiotic and prevention of Pseudomonas aeruginosa infections: a randomized, double- blind, placebocontrolled pilot study in intensive care unit patients. Crit Care 2008;12:R69

26. Klarin B, Molin G, Jeppsson B and Larsson A. Use of the probiotic Lactobacillus plantarum 299 to reduce patho- genic bacteria in the oropharynx of intubated patients: a randomised controlled open pilot study. Crit Care 2008;12:R136.

27. Knight DJ, Gardiner D, Banks A, Snape SE, Weston VC Bengmark S, et al. Effect of synbiotic therapy on the incidence of ventilator associated pneumonia in criti- cally ill patients: a randomised, double-blind, placebo- controlled trial. Intensive Care Med 2009; 35:854-861.

28. Barraud D, Blard C, Hein F, Marcon O, Cravoisy A, Nace L, et al. Probiotics in the critically ill patient: a double blind, randomized, placebo-controlled trial. Intensive Care Med 2010; 36:15401507.

29. Xu K, Cai H, Shen Y, Ni Q, Chen Y, Hu S, et al. Management of corona virus disease-19 (COVID-19): the Zhejiang experience. Zhejiang Da XueXue Bao Yi Xue Ban 2020; $49: 1$.

30. De Simone C, Ciardi A, Grassi A, Lambert Gardinin S Tzantzoglou S and Trinchieri V. Effect of Bifidobacterium bifidum and Lactobacillus acidophilus on gut mucosa and peripheral blood B lymphocytes. Immunopharmacol Immunotoxicol 1992; 4:331-340.

31. Schiffrin EJ, Rochat F, Link-Amster $H$, Aeschlimann JM and Donnet-Hughes A. Immunomodulation of human blood cells following the ingestion of lactic acid bacteria. J Dairy Sci 1995;78:491-497.

32. Majaama M and Isolauri E. Probiotics: a novel approach in the management of food allergy. J Allergy Clin Immunol 1997; 99:179-185.

33. Isolauri E, Arvola T, Sutas Y, Moilanen E and Salminen S. Probiotics in the management of atopic eczema. Clin Exp Allergy 2000; 30:1605-1610.

34. National Health Committee of the People's Republic of China and National Administration of Traditional Chinese Medicine. Diagnostic and therapeutic guidance for 2019 novel coronavirus disease (version 5). Available from: URL:http://www.nhc.gov.cn/ yzygj/s7653p/202002/d4b895337e19445f8d728fcaf1e3e13a/ files/ab6bec7f93e64e7f998d802991203cd6.pdf.Date accessed: May 12, 2020

35. Mak JWY, Chan FKL and Siew CN. Probiotics and COVID-19: one size does not fit all. Lancet Gastroenterol Hepatol April 24, 2020.

https://doi.org/10.1016/S2468-1253(20)30122-9.

36. Yan F and Polk DB. Probiotics and immune health. Curr Opin Gastroen 2011; 27: 496-501.

\section{Authors Contribution:}

AMS- Conceptualized and designed the study, literature search, prepared first draft of the manuscript, critical revision of the manuscript; DC- Conceptualized the study, Interpretation, critical revision of the manuscript; RG- Concept of the study, literature search, review of the study.

\section{Work attributed to:}

Human Biology and Human Genetics Laboratory, Department of Anthropology, University of Calcutta.

\section{Orcid ID:}

Dr. Aditi Munmun Sengupta- (1) https://orcid.org/0000-0003-4142-5331

Dr. Diptendu Chatterjee- (D) https://orcid.org/0000-0002-5884-1158

Ms. Rima Ghosh- io https://orcid.org/0000-0001-8311-0050

Source of support: None, New Delhi, Conflicts of Interest: The authors declare that the study was conducted in the absence of any commercial or financial relationships that could pose as a potential conflict of interest. 